\title{
Anticipated Pain and Pain Experience Among Orthodontic Patients: Is there any Difference? Kafle $D,{ }^{1}$ Rajbhandari $A^{2}$
}

\author{
${ }^{1}$ Department of Dentistry, Kathmandu University \\ School of Medinine, Nepal. \\ ${ }^{2}$ Department of Orthodontics,People's Dental \\ College and Hospital
}

\section{Corresponding Author}

Dashrath Kafle

Department of Dentistry

Dhulikhel Hospital, Kathmandu University Hospital Kathmandu University School of Medical Sciences Dhulikhel Nepal.

E-mail:dashrath07@yahoo.com

\section{Citation}

Kafle D, Rajbhandari A. Anticipated Pain and Pain Experience Among Orthodontic Patients: Is there any Difference? Kathmandu Univ med J 2012;38(2):7173.

\begin{abstract}
Background

Orthodontic treatment is taken as a painful procedure by most of the patients. The pain can be experienced during different procedures like separator placement, banding, bonding, extraction as well as arch wire activation and debonding. There are very few studies done on the anticipated pain and pain experienced among mentioned orthodontic procedures.
\end{abstract}

\section{Objectives}

To compare the anticipated pain and pain experience among the patients going for comprehensive orthodontic treatment.

\section{Methods}

Total 45 patients going for comprehensive orthodontic therapy are enrolled into the study. They are given a $100 \mathrm{~mm}$ Visual Analogue Scale (VAS) for pain. The anticipated pain as well as perceived pain after different orthodontic procedures are recorded on the VAS by patients and returned back to orthodontic office. The data are analyzed by SPSS 16.00 software by paired and independent t-test for the statistical significance.

\section{Results}

The result showed that there is significant difference between the anticipated pain before orthodontic treatment and the pain experienced following orthodontic treatment. It also showed that perception of pain between two sexes is significantly different. The comparison of anticipated pain among male and female does not show any significant difference, however the pain felt after separator placement as well as after orthodontic bonding is significantly different in two sexes.

\section{Conclusion}

The level of anticipated pain before orthodontic treatment is higher than the real pain experienced after orthodontic procedures. So it is better to counsel and explain the patients about the orthodontic treatment and procedures.

\section{KEY WORDS}

Anticipated Pain, Orthodontic, Visual analogue scale

\section{INTRODUCTION}

The International Association for the Study of Pain has defined it as an unpleasant sensory and emotional experience associated with actual or potential tissue damage, or described in terms of such damage. Orthodontic treatment is always taken as a painful procedure by patients even before the start of the treatment. ${ }^{1,2}$ It is reported that $95 \%$ of the orthodontic patients experience varying degree of pain during orthodontic treatment..$^{2-4}$ It is also reported that patients' main cause of deterring from orthodontic treatment is pain. ${ }^{5,6}$ However the intensity of the pain differs from patient to patient. It depends upon age, sex, race, emotional sate as well as the cultural background. ${ }^{1,4}$ One survey rated pain as the greatest dislike during treatment and fourth among major fears and apprehensions prior to orthodontic treatment. ${ }^{7}$ Orthodontic treatment starts from 
the stage of initial examination till the date of deboning which includes major events like extraction of few teeth, separator placement, bonding and banding, arch wire placement and activation as well as deboning. ${ }^{8}$ So patients are exposed to pain stimuli throughout the orthodontic treatment. Being responsible clinician orthodontists should know the painful effects of the each of the procedure and know the measures to mitigate pos-procedural pain. There are several studies which have shown that pre-procedural administration of analgesics significantly reduces the postprocedural pain..$^{9-14}$

Furstman et al suggested that periodontal pain was caused by a process of pressure, ischemia, inflammation, and edema. ${ }^{15}$ Orthodontic treatment exerts pressure on teeth due to which prostaglandins are released which are the mediators of inflammatory process and hence pain. ${ }^{16,17}$ The purpose of our study is to compare the anticipated pain before starting orthodontic treatment to that of intensity of pain experienced following orthodontic treatment.

\section{METHODS}

Total 45 patients going for comprehensive orthodontic treatment are enrolled into the study. Patients with fixed functional appliances, removable appliances, on long term systemic medications as well as mentally handicapped patients are excluded from the study.

All the patients are given a leaflet with Visual Analogue Scale (VAS) for Pain. The patients are requested to report the degree of pain they anticipated or experienced on the scale. The scale is $100 \mathrm{~mm}$ with markings from 0 to 10 , where 0 on the scale denotes the condition of no pain and 10 denotes the maximum tolerable pain a person can experience. Patients are requested to note the pain they anticipated before treatment and real pain experienced after each orthodontic procedure.

The data are collected on excel sheet and later transferred to SPSS 16.0 software. Statistical analysis is done by paired t-test to compare the data. $P$ value is kept 0.05 for the statistical significance.

\section{RESULTS}

The result comparing the anticipated pain and pain following orthodontic bonding is shown on table 1 . It is found that there is a statistically significant difference between the anticipated pain and the real pain experienced after orthodontic bonding, $p$ value 0.001.The comparison of anticipated pain among male and female does not show any significant difference, however the pain felt after separator placement as well as after orthodontic bonding is significantly different in two sexes, $p$ value 0.004 and 0.005 respectively as shown in table 2 . The comparison of orthodontic pain and pain following extraction is non significant. (table 3)
Table 1. Comparison of anticipated pain and experienced pain.

\begin{tabular}{llrlll|} 
& N & Mean & $\begin{array}{l}\text { Standard } \\
\text { deviation }\end{array}$ & t-value & p-value \\
\hline Anticipated & 45 & 6.2889 & 2.74377 & 3.608 & $0.001^{* *}$ \\
\hline pain & & & & \\
\hline Pain after & 45 & 4.3111 & 2.77834 & \\
\hline $\begin{array}{l}\text { bonding } \\
\text { * Significant }\end{array}$ & & & \\
** Highly Significant & $\begin{array}{r}\mathrm{p}<0.05 \\
\mathrm{p}<0.01\end{array}$ & \\
\hline
\end{tabular}

Table 2. Comparison of pain between two sexes.

\begin{tabular}{|c|c|c|c|c|c|}
\hline & $\begin{array}{l}\text { Sex } \\
M, F\end{array}$ & Mean & $\begin{array}{l}\text { Std.devia- } \\
\text { tion }\end{array}$ & t-value & p-value \\
\hline Anticipated & 10 & 5.4000 & 3.02581 & -1.067 & .292 \\
\hline pain & 34 & 6.4412 & 2.61917 & & \\
\hline Pain after & 10 & 4.5000 & 3.02765 & -3.034 & $.004 * *$ \\
\hline seperator & 29 & 7.2759 & 2.29746 & & \\
\hline Pain after & 10 & 2.3000 & 1.94651 & 2.949 & $0.005 * *$ \\
\hline bonding & 34 & 5.0000 & 2.68554 & & \\
\hline Pain after & 5 & 3.8000 & 3.34664 & -.800 & .433 \\
\hline extraction & 18 & 5.2778 & 3.72283 & & \\
\hline $\begin{array}{l}* \text { Significant } \\
* * \text { Highly Signi }\end{array}$ & ficant & \multicolumn{2}{|c|}{$\begin{aligned} p & <0.05 \\
p & <0.01\end{aligned}$} & & \\
\hline
\end{tabular}

Table 3. Comparison of orthodontic pain and extraction pain.

\begin{tabular}{|c|c|c|c|c|c|}
\hline & $\mathbf{N}$ & Mean & $\begin{array}{l}\text { Standard } \\
\text { deviation }\end{array}$ & t-value & p-value \\
\hline Orthodontic & 23 & 4.7826 & 2.96888 & -.188 & .853 \\
\hline \multicolumn{6}{|l|}{ pain } \\
\hline Extraction & 23 & 4.9565 & 3.62414 & & \\
\hline pain & & & & & \\
\hline
\end{tabular}

\section{DISCUSSION}

Usually patients perceive orthodontic treatment as a very painful treatment procedure. For the lay person the array of complex brackets, bands, wires, springs as well as elastics seem to be very complicated. Many patients do not want to carry orthodontic treatment because of the fear of pain. It is reported in the study of Kvam that $95 \%$ of the patients experience pain after orthodontic treatment out of which very few only experience severe pain. ${ }^{2}$ In our study also $97 \%$ of the orthodontic patients had some fear of pain as well as same percentage of patients experienced pain following orthodontic treatment among which only $11 \%$ of the patients received severe pain VAS score $8-10 .^{2}$ Our study has shown that the real pain experienced by orthodontic patients is significantly much less than the anticipated pain. The anxiety always plays a vital role on the experience of pain. We should always try to reduce the anxiety level of the patients by proper counseling and explanation of the procedure we are going to deliver. The level of pain is different among male and female patients. The anticipated pain seems to be slightly higher in females compared to male which is not significant statistically. However pain experienced after orthodontic procedure is significantly higher in females compared to 
males. Likewise pain resulting from separator placement is also felt significantly higher in females than in males. The study of Ngan et al has found no difference on pain perception between two sexes. ${ }^{14}$ The comparison of pain following tooth extraction for orthodontic purpose is not of significant difference among two sexes. That may be due to the administration of analgesics after extraction.

It has been proved that pre-procedural administration of analgesics significantly reduce the level of pain compared to post-procedural administration of analgesics. Preprocedural administration of analgesic reduces the pain threshold and blocks the pain pathway by inhibition of prostaglandin synthesis. Pre-procedural administration of analgesics is not only practiced in orthodontics, it is also practiced in other branches of dentistry e.g., maxillofacial surgery and periodontics. Administering analgesics 2 hours before extraction reduces the post-extraction pain. It is important to know that psychological pain associated

\section{REFERENCES}

1. Krishnan V. Orthodontic pain: from causes to management--a review. Eur J Orthod. 2007 Apr;29(2):170-9.

2. Kvam E, Bondevik $\mathrm{O}$, Gjerdet NR. Traumatic ulcers and pain in adults during orthodontic treatment. Community Dent Oral Epidemiol. 1989 Jun;17(3):154-7.

3. Jones $M$, Chan $C$. The pain and discomfort experienced during orthodontic treatment: a randomized controlled clinical trial of two initial aligning arch wires. Am J Orthod Dentofacial Orthop. 1992 Oct;102(4):373-81.

4. Scheurer PA, Firestone AR, Burgin WB. Perception of pain as a result of orthodontic treatment with fixed appliances. Eur J Orthod. 1996 Aug;18(4):349-57.

5. Kluemper GT, Hiser DG, Rayens MK, Jay MJ. Efficacy of a wax containing benzocaine in the relief of oral mucosal pain caused by orthodontic appliances. Am J Orthod Dentofacial Orthop. 2002 Oct;122(4):359-65.

6. Keim RG. Managing orthodontic pain. J Clin Orthod. 2004 Dec;38(12):641-2.

7. O'Connor PJ. Patients' perceptions before, during, and after orthodontic treatment. J Clin Orthod. 2000 Oct;34(10):591-2.

8. Normando TS, Calcada FS, Ursi WJ, Normando D. Patients' report of discomfort and pain during debonding of orthodontic brackets: a comparative study of two methods. World J Orthod. Winter;11(4):29-34.

9. Ousehal L, Lakhdar A, Elquars F. [Comparison of the effect of paracetamol and ibuprofen on orthodontic pain]. Int Orthod. 2009 Jun; $7(2): 193-206$. with orthodontic treatment can be reduced by proper explanation and counseling where as real pain experienced by patients can be reduced by administering analgesics before major orthodontic procedures like separator placement, banding, as well as arch wire placement. The study of Bernhardt et al has found that pain perceived after orthodontic treatment is greater than that of following extraction. We compared the orthodontic pain and pain following extraction of teeth for orthodontic purpose where the result is non significant as in study by Bernhardt et al. ${ }^{18}$

\section{CONCLUSION}

The anticipated pain before any orthodontic treatment can be really higher than the real pain experienced after orthodontic procedures. With the same procedure administered, female patients have more chance of experiencing pain than the male patients.

10. Patel S, McGorray SP, Yezierski R, Fillingim R, Logan H, Wheeler TT. Effects of analgesics on orthodontic pain. Am J Orthod Dentofacial Orthop. Jan;139(1):53-8.

11. Polat O, Karaman Al. Pain control during fixed orthodontic appliance therapy. Angle Orthod. 2005 Mar;75(2):214-9.

12. Polat O, Karaman Al, Durmus E. Effects of preoperative ibuprofen and naproxen sodium on orthodontic pain. Angle Orthod. 2005 Sep;75(5):791-6.

13. Salmassian R, Oesterle LJ, Shellhart WC, Newman SM. Comparison of the efficacy of ibuprofen and acetaminophen in controlling pain after orthodontic tooth movement. Am J Orthod Dentofacial Orthop. 2009 Apr;135(4):516-21.

14. Ngan P, Kess B, Wilson S. Perception of discomfort by patients undergoing orthodontic treatment. Am J Orthod Dentofacial Orthop. 1989 Jul;96(1):47-53.

15. Furstman L, Bernick S. Clinical considerations of the periodontium. Am J Orthod. 1972 Feb;61(2):138-55.

16. Sergl HG, Klages $U$, Zentner A. Pain and discomfort during orthodontic treatment: causative factors and effects on compliance. Am J Orthod Dentofacial Orthop. 1998 Dec;114(6):684-91.

17. Xiaoting L, Yin T, Yangxi C. Interventions for pain during fixed orthodontic appliance therapy. A systematic review. Angle Orthod. Sep;80(5):925-32.

18. Bernhardt MK, Southard KA, Batterson KD, Logan HL, Baker KA, Jakobsen JR. The effect of preemptive and/or postoperative ibuprofen therapy for orthodontic pain. Am J Orthod Dentofacial Orthop. 2001 Jul;120(1):20-7. 